\title{
The Syntactical Realization Mode of Sentence-Level Functional Categories in Irish*
}

\author{
Hongcheng Ma \\ School of Chinese Language and Culture \\ Zhejiang International Studies University \\ Hangzhou, China
}

\begin{abstract}
Sentence-level functional categories are the functional category with specific grammatical effects by the means of the whole-sentence, which usually include negative category, interrogative category and assumption category, etc. The categories in Irish all could be realized through adjoining operation device on sentence-initial position. The pre-predicate position usually coincides with sentence- initial position under the influence of normative word-order in Irish, and thus it makes a difference to syntactic operation device on this position. However, at least to negative category, there is only the adjoining negation operation on sentence-initial position or pre-predicate position presently, and the operation taking up sentence-final position or the corpus using movement or reduplication has not been found.
\end{abstract}

Keywords-sentence-level functional categories; irish; the susceptible position

\section{INTRODUCTION}

In general, grammatical category could be roughly divided into lexical category and syntactic category, and the functional category expressed by the form of whole-sentence (sentence or clause) should belong to the latter. Because of the multi-dimensional comprehension to "sentence function", it causes grammatical category making tangled demarcation among semantic, grammatical and pragmatic level all the time. Xu (2010) has ever drawn up a distinguishing criterion: "Sentence function" in grammatical meaning are only those with specific grammatical effects whose main manifestation is doing syntactic operation such as adjoining, movement and reduplication on the susceptible position of sentenceinitial, pre-predicate and sentence-final in form. The sentence grammatical function here is actually the sentencelevel function category what we discussed. According to the criterion, the sentence-level category that we could determine temporarily includes negative, interrogative and assumption at least.

The three syntactic operation devices and the three syntactic operation positions which sentence-level function

\footnotetext{
* Studies on the Syntactic Realization Position of Chinese Sentence Functional Category Based on Corpus, Supported by the China National Foundation in Social Sciences ,( Grant No. 15BYY140).

${ }^{1}$ See Ma and Li (2011) for relevant introductions and Xu $(2006,2010)$ for specific references.
}

category has involved have five possible matching ways below: sentence-initial adjoining, pre-predicate adjoining, sentence-final adjoining, pre-predicate movement and prepredicate reduplication. Any language is the instantiated results of the five ways. ${ }^{2}$ Of course, the inference is only a theoretical assumption at present, needing more discussion on "sentence-level category" and more language facts to support it. The article would regard Irish that genetics and word-order type are different from Chinese as study subject to continue to discuss the issue. ${ }^{3}$

\section{NEGATIVE CATEGORY IN IRISH}

Irish is the official language in Ireland, belonging to the northern dialect in Celtic branch of Indo-European family ( that is Gerd ), and its basic word order is VSO. In semantic, its negative composition could be divided into two categories similar to Chinese. One is the general negative composition "bu"(no), which mainly includes adverb ní / níor (cha / char is used in Ulster, respectively used in present tense and past tense) and conjunction nach / nár (respectively used in present tense and past tense). The other is imperative negative composition "bie" (don't), which mainly has adverb ná.

(1) $\mathrm{Ne}$ disputalfaidh me leat.

NEG argue. FUT I and You

I don't argue with you. ( Stenson,1990:180 )

(2) Níor iarr mé gar ar bith.

NEG.PST ask I favour at all

I asked for no favour. ( Acquaviva ,1996:287 )

(3) Níor ól mé fuisce.

NEG drink. PST I Whisky

I don't drink Whisky.

${ }^{2}$ Refer to Xu (2005: 227) for more details.

${ }^{3}$ Relevant Irish negative category has been discussed (Ma, 2014: 98103) . To discuss more clearly here, it doesn't avoid partial repetition, and still used simple common sentences. Irish corpus without specific sources and partial explanations in the article are all from the Internet http://nualeargais.ie/gnag/gram.htm (Irish Grammar). 
(4) Ná hól fuisce!

$$
\begin{aligned}
& \text { NEG drink Whisky } \\
& \text { Don't drink Whisky. }
\end{aligned}
$$

According to examples, tense and semantic type are different, but the linear position of sentence negative composition is at the beginning of sentence without exception. In addition, the verb's pronunciation sometimes should weakened accordingly, generally realized through adding $h$ in front of vowel.

Note that Irish basic word order is VSO, different from English, German and other Indo European languages. Though the word order would change, it doesn't due to the syntactic generally, but only to show special structure like emphasizing. The most common phenomenon is using copula composition to emphasize cleft construction of subject, object, verbal nouns and etc.

(5) a. Tógann sé teach.

build he house

He builds a house.

b. Is teach a thógann sé.

COP house build he

He is building a house.

Irish copula compositions are only used when nouns, pronouns or adjectives are used as predicate, including present tense (is), past tense $(b a)$ and subjunctive mood ( gura) the three basic forms. The copula compositions connecting subject and predicate in Irish are related to ist in German and is in English, and they could translate basically, but they are more suitable to be referred as independent auxiliary words instead of the real verbs, at most as incomplete verbs. The example (5a) is a general sentence of VSO word order, while example (5b) is a cleft sentence consisted of "copula clause + relative clause". In the latter, the emphasized composition teach (house) moves forward directly behind the copula $i s$, being as nominal predicate in copula clause, and the relative clause behind is as the subject in copula clause. The word order in the whole-sentence could be regarded as "copula $+\mathrm{V}+\mathrm{S}$ ", generally according with basic word order. The situation that the word order change in Irish could show its coerciveness and dominance in VSO word order, and the existence of copulas is to make up syntax defects that nominal predicate brings about.

Because of the word order rules that verbs to sentenceinitial in Irish, the negative composition of sentence-initial in common sentence is just ahead predicate, so whether the position is as pre-predicate or not? As we all known, prepredicate's confirmation is different from obvious sentenceinitial and sentence-final. In principle, it could be defined as I in syntactical tree diagram, while the position is different in linear order arrangement. It is the position of auxiliary verbs or central words in English, while that of the left-most predicate adverbial in Chinese. ${ }^{4}$ Although the identification is only descriptive category roughly for the present, and may not cover all languages, Irish and English dialect should belong to the same category. The two languages both have function elements such as sentence central word's tense and consistent state, and they also need the support of entity vocabulary items to undertake and integrate.

All the verbs with single syllable in Irish have 1st conjugation. Their standard form not only has differences on consistent state like singular and changes on tense elements like present tense and past tense, indicative and subjunctive mood, but also needs entity vocabulary to undertake. For instance, example (6) shows past tense in indicative and first-person singular, using verb's root-form ól. However, because the past tense's verbs in Irish generally need to weaken pronunciation, it added a prefix $d^{\prime}$ showing consonant weakened. Example (7) shows future tense and second-person singular, and verbs need to add suffix faidh behind words.

(6) d'ól mé.

\section{Drink. PST I}

I drunk.

(7) Ólfaidh tú fuisce.

Drink. FUT you Whisky

You are to drink Whisky.

Actually the conjugation is the result after syntactic operation. Because there is no auxiliary verb in front of predicate, central verb ól moves up through " $\mathrm{V} \rightarrow \mathrm{I}$ ” to I to undertake the sentence's central function elements. In example (6), past tense in indicative, first-person singular, other elements ( zero form) and the verb moved in ól integrate to $o l$ in the position of pre-predicate. In example (7), future tense in indicative, second-person singular, other elements (-faidh) and the verb moved in ól integrate to olfaidh in the position of pre-predicate. In the early stages when sentences generated, the sentence's form should be "[ function element -faidh $+o ́ l]$ tú fuisce arís" . In the late processing, "[ function element -faidh $+o ́ l]$ ” combine and are rewrote to olfaidh. That is to say, it's the word formation triggered later that makes the sentence appeared as the form we saw. According to the generate processing, in linear word order, the verb ól integrated by tense and consistent state takes exactly the beginning predicate's grammatical position in the sentence, where pre-predicate is clear.

That is, when only predicates exist, the position that predicates take is that of pre-predicate. So when auxiliary verbs appear, how about the pre-predicate's position?

$$
\begin{aligned}
& \text { (8) Is féidir liom Gaeilge a scríobh. } \\
& \text { COP.PRES can I. PP Irish (prep.) write. } \\
& \text { VN }
\end{aligned}
$$

${ }^{4}$ Refer to Xu and Li (2010: 105) for more details. 
I can write Irish.

(9) Tá orm imeacht.

AUX.PRES I.PP go. VN

I have to go.

Modal verbs in Irish are rarely used alone. In example (8), modal verb féidir is used together with copula is to express the meaning of modal auxiliary in Chinese. "Write" as notional verb in the sentence used non-finite form, losing the predicate's function, and modal verb acted as predicate. The copula in the sentence-initial with tense elements takes up the position of pre-predicate. Example (5b) is the same. Pre-predicate's determination is more obvious in example (9). "Go" as notional verb also used gerund form, losing the predicate's function, while what realized the predicate's function in the sentence is auxiliary, and the auxiliary showed the existence of tense elements. So, auxiliary in the sentence-initial is exactly where the pre-predicate. In conclusion, only when auxiliary in the sentence-initial can it becomes the center showing sentence's function, i.e the position of sentence-initial and that of pre-predicate are overlapping.

When negative composition and auxiliary co-occur, negative composition' $\mathrm{s}$ syntactical function is the same as auxiliary' s copula, where it takes in syntax is also the overlapping part of sentence-initial and pre-predicate. Compare example (8) with (10), and example (11) with (12).

(10) ní féidir liom Rúisis a scríobh.

NEG can I. PP Russian (prep.) write. VN

I can't write Russian.

(11) Is gá dom é a dhéanamh. COP need I. PP it (prep.) engage. VN

I need to engage it.

(12) Ní gá duit é a dhéanamh.

NEG need you. PP it (prep.) engage. VN

You don't need to engage it.

The negative composition in the sentence-initial is also the sentence' function center, i.e pre-predicate's position. The expression is coincide with English: When negative composition expresses negative category, negative composition will replace central verb to take up prepredicate's position. At the same time, negative composition in Irish is also in the sentence-initial. Then compare example (7) and example (13) below, we could notice the performance when negative composition in the susceptible position more clearly. It is the same for example (14) in Old Irish. As the sentence's central composition, I, its accordant function elements could take the same position with negative composition, i.e sentence-initial is where prepredicate, and the two elements of functional category took the overlapping position of sentence-initial and prepredicate together.
(13) Ní ólfaidh tú fuisce arís.

NEG drink. FUT you Whisky again

You don't intend to drink Whisky again.

(14) Ní-m charat-sa.

NEG- INF.1SG love. PRES.3PL.CONJ -

\section{EMPH.PART.1SG}

They do not love me. (Newton ,2009:164)

The confirmation of pre-predicate's position in Irish could also get support from word order's performance of predicate modifier. The special sensitivity of pre-predicate's position causes it can't allow the modifier that triggers the whole-sentence to stay here when it doesn't deal with in the sentence-level functional category. The modifier arís in example (13) is a limitation to predicate's meaning in semantic, but it can't be pre-predicate in front of predicate in syntactical position.

However, as it mentioned above, under special cases such as expressing emphasis, Irish word order would have some changes. Example (5b) is to emphasize on object, using copula to guide copula clause in affirmative sentence, and sentence-initial's copula is at the position of prepredicate. Example (15) and (16) showed the performance of emphasizing object in negative sentence: negative composition's pre-predicate's position doesn't change, but sentence-initial is taken up by the emphatic part. The change is the result of emphasizing on pragmatics instead of syntax, and it's rare to appear the situation that goes against VSO syntactical rules. So, we could think that negative composition's syntactical position in Irish is generally in the overlapping position of sentence-initial and pre-predicate. Only under special cases of pragmatic enforcement can negative composition take the pre-predicate's position.

(15) a. Ní bhfuair mé litir.

NEG receive I letter

I didn't receive the letter.

b. Litir ní bhfuair mé.

Letter NEG receive I

I haven't received a letter.

(16) a. Ní raibh mé ag saothrú pingine.

NEG be I (prep.) earn. VN penny

I didn't earn a penny.

b. Pingin ní raibh mé a shaothrú.

Penny NEG is I (prep.) earn. VN

I didn't earn a penny.

What should say is that the scope of negative composition expressing the sentence-level negative category 
isn't definitely main clause, and it also includes clauses acted as various subordinate clauses. So, negative composition in sentence-initial could also refer to the sentence-initial of subordinate clauses. Example (17) and (18) respectively are present tense's compound sentence and past tense's compound sentence. The same with conjunction go/gur in affirmative structure, negative clause's negative composition nach/ nár also has effect on connect main clause and subordinate clause. But in the term of expressing negative function, it's obvious that it still in the overlapping position of sentence-initial and pre-predicate in clause.

$$
\begin{aligned}
& \text { (17) a. Sílim go bhfuil tú sásta. } \\
& \text { I think. PRES (conj.) be. PRES you }
\end{aligned}
$$

happy

I think you are happy.

$$
\text { b. Sílim nach bhfuil tú sásta. }
$$

I think. PRES NEG be. PRES you happy

I don't think you are happy.

$$
\text { (18) a. Bhí mé sásta gur shíl tú é. }
$$$$
\text { Be. PST I glad (conj.) think. PST you it }
$$

I'm glad you can think so.

b. Bhí mé sásta nár shíl tú é.

Be.PST I glad NEG think. PST you it

I'm glad you don't think so.

Irish negative composition is usually in the overlapping position of pre-predicate and sentence-initial, causing syntactic operation device of expressing negative category suffered syntactical position's limitation. According to the analysis to pre-predicate, it is generally recognized that because the limitation of movement condition and lexical condition, the two susceptible position sentence-initial and sentence-final could only do a syntactic operation "adjoining markers", while pre-predicate's position could provide platform for more types of syntactic operation such as movement or reduplication. However, the view is reached based on the situation when three susceptible positions exist independently. If pre-predicate is overlapped with sentenceinitial, the syntactic performance in susceptible position will change accordingly. Firstly, the means of adjoining markers won't be influenced. Secondly, the means of movement in the allowed pre-predicate in the past because of the inexistence of movement foothold lost motivation syntactically. ${ }^{5}$ Lastly, the means of reduplication aimed at grammatical composition in the pre-predicate will continue to use in the sentence-initial. So the syntactic function in the overlapping position is not sentence-initial's function adding pre-predicate's function simply, and its relevant

\footnotetext{
${ }^{5}$ With regard to Irish verbs' movement, it's generally acknowledged that only the movement from $\mathrm{V}^{0}$ to $\mathrm{I}^{0}$ exists instead of the movement from $\mathrm{I}^{0}$ to $\mathrm{C}^{0}$. Refer to McCloskey (1996) and Newton (2008) for relevant discussion.
}

syntactic device should include adjoining markers and reduplication.

As the reduplicate form of lexical device, it's general that most verbs could use reduplication to express future tense or past tense in Old Irish. ${ }^{6}$ Besides, the answers to yes-no questions in Irish don't use yes or no but the reduplicate form to predicate without subjects and objects. See example (19).

(19) a. An ólann sé bainne? - Ólann.

QU drink. IND.PRES he milk drink Does he drink milk?- Yes.

b. An ólann sé fuisce? - Ní ólann.

QU drink. IND.PRES he Whisky NEG

drink

Does he drink Whisky?- No.

However, the two forms are not the real reduplication device. Limited by what we observed, we haven't find the usage of the syntactic device in the overlapping position of pre-predicate and sentence-initial. In word, the most common syntactic device expressing sentence-level functional category in Irish is adjoining grammatical marks. It could be proved further in the realization of categories like interrogative and assumption.

\section{INTERROGATIVE CATEGORY AND ASSUMPTION CATEGORY IN IRISH}

See interrogative category firstly.
(20) Nár
ól
tú fuisce?
QU.NEG drink. IND.PST you Whisky

Didn't you drink Whisky?

The expression of no-asking questions in Irish is to adjoin relevant interrogative mark in the sentence-initial directly, like example (19). What should pay attention to is that Irish has words expressing negative interrogation specially, like nár in example (20). It remains to see whether nár is the fusion of negative mark and interrogative mark.

$$
\begin{aligned}
& \text { (21) a. *Rinne cé é? } \\
& \text { Do. PST who it } \\
& \text { Who did it? } \\
& \text { b. Cé a rinne é? } \\
& \text { Who ( relative auxiliary) do. PST it } \\
& \text { Who did it? }
\end{aligned}
$$
b. Cé a
rinne
é?
Who ( relative auxiliary) do. PST it
Who did it?

$$
\text { (22) Cár chuir tú é? }
$$

${ }^{6}$ Refer to Lewis, 1984, the loss of reduplication in middle of Irish, Proceedings of the Harvard Celtic Colloquium, [2013-05-23] http://www.jstor.org/pss/20557149 for more details. 
Where put. PST you it

Where did you put it?

The expression of Wh-questions in Irish is also using interrogative in sentence-initial directly, like example (21) and (22). However, in order to accord with VSO word order rules, Wh-questions are always showing using cleft structure, divided into two components: copula clause + relative clause. Copula clause ostensibly includes only interrogative, actually also including copula part of zero form. The rest is relative clause, guided by relative auxiliary $a / a r$, and served as formal subject of copula clause. The interrogative $c e ́$ in example (21) actually represents "Who's this". The interrogative cár in example (22) actually is the mixed form $(c a ́+a r=c a ́ r)$ of interrogative composition $c a ́$ and relative auxiliary a/ar.

$$
\text { (23) a. An ólann tú tae nó caife? }
$$

QU drink. PRES you tea or coffee

Do you drink tea or coffee?

b. An tae nó caife a ólann(s) tú?

QU tea or coffee drink. PRES you

Do you drink tea or coffee?

The expression of alternative question in Irish, no matter whether alternative objects move in front of predicate because of emphasis or not, they all must adjoin interrogative mark in sentence-initial, like example (23). Except the direct question above, let's see the expression of indirect question.

(24) Níl a fhios agam an ólann sé fuisce.

Whisky

NEG know I. PP QU drink. PRES he

I don't know whether he drink Whisky.

(25) Níl a fhios agam cá bhfuil tú.

NEG know I. PP where be. PRES you

I don't know where are you from.

Example (24) and (25) are negative declarative sentences, the expression of negative category is to adjoin negative marks in the sentence-initial. Subordinate clause is indirect question functionally, while the expression is to use interrogative composition in the subordinate clause's sentence-initial directly, generally in the pre-predicate in front of predicate. So, no matter direct questions like yes-no questions, Wh-questions, and alternative questions or indirect questions in the form of clauses in Irish, the realization approaches of interrogative category are to adjoin relevant interrogative composition in the sentenceinitial.

Then assumption category.

(26) a. Má fheiceann tú an fear.
If see. PRES you this man

If you see this man

b. Mura bhfeiceann tú an fear

If not see. PRES you this man

If you don't see this man

(27) a. Má d'ól tú fuisce.

If drink. PST you Whisky

If you drunk Whisky

b. Mura ól tú fuisce

If not drink. PST you Whisky

If you didn't drink Whisky

According to Dong and $\mathrm{Xu}$ (2009) in the terms of crosslanguage, the most common syntactic device of assumption category's expression is adjoining. Example (26) and (27) are the condition parts of common assumptive sentences in Irish, representing the realized typical ways in assumption category. The two respectively are present tense and past tense, and $\mathrm{a}$ and $\mathrm{b}$ respectively belong to assertive category and negative category. It doesn't consider the question on the source of mura expressing assumptive function for the present, but it can be seen clearly that the expression of assumption category is to adjoin relevant grammatical composition in the sentence-initial directly.

Obviously, the three sentence-level functional categories we defined temporarily negative, interrogative and assumption could be realized through using adjoining device in the sentence-initial's susceptible position. Because of the very strict VSO word order in Irish, the pre-predicate susceptible to sentence's function similarly is often overlapped with sentence-initial, causing changes to the syntactic devices expressed in the position. However, at least to sentence-level negative category, there is only one device that adjoining negative composition in the sentenceinitial or pre-predicate at present. It haven't find that using sentence-final or other positions and corpus using syntactic devices like movement or reduplication.

Abbreviations in the article: $1 \mathrm{SG}$ - first person singular;3PL - third person plural; AUX - auxiliary; CONJconjugation ; COP - copula; EMPH-emphasis; FUT - future; IND - indicative; INF-infinitive ;NEG - negation/negative; QU - question; PART - partitive; PST - past; PP prepositional phrase; PRES - present; VN - verbal nouns

\section{REFERENCES}

[1] Acquaviva, Paolo.Negation in Irish and the Representation of Monotone Decreasing Quantifiers. In: Robert D. Borsley and I. Roberts (eds.) The Syntax of the Celtic Languages, Cambridge: Cambridge University Press, 1996.

[2] Carnie, A. H. Non-verbal Predication and Head-movement. PhD Thesis, Massachusetts Inst. of Technology, Cambridge, 1995.

[3] Carnie, Andrew, Heidi Harley \& Elizabeth Pyatt. VSO order as raising to out of IP - some evidence from Old Irish. In Carnie and 
Guilfoyle (eds) : The Syntax of Verb Initial Languages. Oxford University Press,2000,pp.39-60.

[4] Chomsky, N. Derivation by phase. In Kenstowicz (ed.), Ken Hale: A Life in Language. Cambridge, MA: MIT Press,2001,pp.1-52.

[5] Dillon, Brian.The Irish language in RRG: an overview. [2013-06-03] http://linguistics.buffalo.edu/people/faculty/vanvalin/rrg/dillon_thesis .pdf.2004.

[6] Dong,Xiuying and Jie Xu.A Cross-language Comparison of the Syntactic Operation of Hypothetical Sentences, Chinese Linguistics, 2009,pp.4:67.(in Chinese)

[7] Ma,Hongcheng and Dandi Li.On the Syntactic Realization of Sentential Negative Category In Chinese Languages, Zhejiang Academic Journal,2011,pp.3. (in Chinese)

[8] Ma,Hongcheng. On the Syntactic Position of Negative markers and the Relevant,Beijing :China Social Sciences Press,2014.(in Chinese)

[9] McCloskey, James .On the Scope of Verb Movement in Modern Irish, NLLT 14: 47-104,1996.

[10] Newton, Glenda. Motivating the loss of V-to-C movement in Old Irish. [2012-09-13] http://conf.ling.cornell.edu/DiGSX/abstracts/Newton.pdf.2008.

[11] Newton, Glenda .Accounting for do-support post-Syntactically: evidence from Old Irish, University of Pennsylvania Working Papers in Linguistics: Vol. 15: Iss. 1, Article 19,2009.

[12] Stenson, N. Phrase structure congruence, government, and IrishEnglish code-switching. In: R.Hendrick ed., The syntax of the modern Celtic languages, pp.167-97. Syntax and Semantics 23. San Diego: Academic Press, 1990.

[13] Xu, Jie. Three Sensitive Positions in a Sentence and Question-A Cross-Linguistic Perspective. In: Shan, Z., Lu, J. (eds.) Studies on Chinese Philology, Beijing :China Social Sciences Press,2005.(in Chinese)

[14] Xu, Jie. Sentence Head and the Predicate-Initial Position, Chinese Linguistics, 3:55-7,2006.(in Chinese)

[15] Xu, Jie. On Nature and Range of Grammar Function of Sentences, Journal of Huazhong Normal University (Humanities and Social Sciences),2,2010. (in Chinese)

[16] Xu, Jie and Ying Li. The "Predicate-Initial" Position in Chinese and Relevant Syntactic Theoretical Issues. Chinese Language and Literature Research,3:105,2010. (in Chinese) 